\title{
WNT regulation of embryonic development likely involves pathways independent of nuclear CTNNB1
}

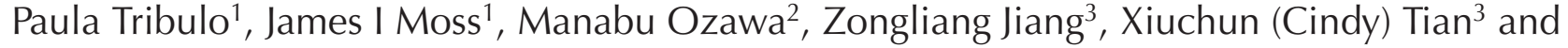 \\ Peter J Hansen ${ }^{1}$ \\ ${ }^{1}$ Department of Animal Sciences, D.H. Barron Reproductive and Perinatal Biology Research Program, and Genetics \\ Institute, University of Florida, Gainesville, Florida, USA, ${ }^{2}$ Laboratory of Developmental Genetics, Institute of \\ Medical Science, University of Tokyo, Tokyo, Japan, and ${ }^{3}$ Center for Regenerative Biology, Department of Animal \\ Science, University of Connecticut, Storrs, Connecticut, USA \\ Correspondence should be addressed to P J Hansen; Email: pjhansen@ufl.edu
}

\begin{abstract}
The bovine was used to examine the potential for WNT signaling to affect the preimplantation embryo. Expression of seven key genes involved in canonical WNT signaling declined to a nadir at the morula or blastocyst stage. Expression of 80 genes associated with WNT signaling in the morula and inner cell mass (ICM) and trophectoderm (TE) of the blastocyst was also evaluated. Many genes associated with WNT signaling were characterized by low transcript abundance. Seven genes were different between ICM and TE, and all of them were overexpressed in TE as compared to ICM, including WNT6, FZD1, FZD7, LRP6, PORCN, APC and SFRP1. Immunoreactive CTNNB1 was localized primarily to the plasma membrane at all stages examined from the 2-cell to blastocyst stages of development. Strikingly, neither CTNNB1 nor non-phospho (i.e., active) CTNNB1 was observed in the nucleus of blastomeres at any stage of development even after the addition of WNT activators to culture. In contrast, CTNNB1 associated with the plasma membrane was increased by activators of WNT signaling. The planar cell polarity pathway (PCP) could be activated in the embryo as indicated by an experiment demonstrating an increase in phospho-JNK in the nucleus of blastocysts treated with the non-canonical WNT11. Furthermore, WNT11 improved development to the blastocyst stage. In conclusion, canonical WNT signaling is attenuated in the preimplantation bovine embryo but WNT can activate the PCP component JNK. Thus, regulation of embryonic development by WNT is likely to involve activation of pathways independent of nuclear actions of CTNNB1.
\end{abstract}

Reproduction (2017) 153 405-419

\section{Introduction}

WNT signaling is a complex signaling system regulated by 19 WNT ligands that interact with a variety of receptors including FZD, ROR, PTK7 and RYK (Cadigan \& Nusse 1997, Logan \& Nusse 2004). Among the downstream signaling cascades are the canonical pathway involving binding of WNT to FZD and recruitment of the co-receptor LRP5 or LRP6 (MacDonald et al. 2009), the planar cell polarity pathway (Veeman et al. 2003, Seifert \& Mlodzik 2007) and calcium signaling pathway (Kühl et al. 2000, Kohn \& Moon 2005). The specific phenotype induced by WNT signaling depends upon the ligands and receptors in play, as well as other specific characteristics of signaling molecules in the cell; thus, a specific WNT-receptor interaction can invoke different outcomes in different cell types (Amerongen et al. 2008).

Canonical WNT signaling is the most well-described pathway for WNT signaling and is crucial for a number of developmental processes through regulation of cell proliferation (Logan \& Nusse 2004), maintenance of pluripotency (Sato et al. 2004, Sokol 2011), differentiation (Liu et al. 2014) and migration (MorosanPuopolo et al. 2014). The central effector of this signaling pathway is CTNNB1, a protein that not only modulates gene expression upon translocation to the nucleus after WNT activation but also serves as a constitutive protein for adherens junctions involved in cell-cell adhesion (Fleming et al. 2001). Nuclear accumulation of CTNNB1 is triggered by the inhibition of its degradation by the proteasome induced by a complex consisting of CKI, GSK3 and APC. Once in the nucleus, CTNNB1 displaces GROUCHO to interact with the transcription factors LEF1 and TCF7 to regulate the transcription of genes involved in cell proliferation and pluripotency such as CCNDBP1 (Tetsu \& McCormick 1999) and MYC (He et al. 1998) respectively. 
WNTs are important regulators of mammalian development, but their role during the preimplantation period has not been resolved. In the mouse, inhibition of canonical WNT signaling does not impair blastocyst development (Huelsken et al. 2000, Kemler et al. 2004, Xie et al. 2008, Lyashenko et al. 2011) or affect identity, expansion or self-renewal of embryonic stem cells (ESCs) (Lyashenko et al. 2011, Wray et al. 2011). In other species, the role of canonical WNT signaling in the preimplantation embryo is less clear because of the experimental use of inhibitors or activators of canonical WNT signaling that could have effects on multiple signaling pathways. In the cow, for example, one inhibitor of GSK3B (which causes activation of the canonical pathway) increased the competence of embryos to develop to the blastocyst stage, whereas another inhibitor reduced development (Aparicio et al. 2000). A physiological antagonist of canonical WNT signaling, DKK1, enhanced the ability of porcine embryos to undergo hatching (Lim et al. 2013), increased trophectoderm (TE) differentiation in pig and cattle (Lim et al. 2013, Denicol et al. 2014) and increased competence of bovine embryos to establish pregnancy after transfer to females (Denicol et al. 2014). Although such results suggest that activation of canonical WNT signaling may inhibit TE differentiation, DKK1 can also regulate other signaling pathways independent of canonical WNT signaling (Caneparo et al. 2007, Tahinci et al. 2007).

In the human embryo, accumulation of CTNNB1 in the nucleus in response to inhibition of GSK3B depends upon the stage of development, with accumulation being attenuated after Day 3 of development and absent in blastocysts (Krivega et al. 2015). Such a result is consistent with findings in the mouse that canonical WNT signaling is not required for development, at least after Day 3, and that developmental changes in the embryo cause a dampening of canonical WNT signaling.

For the current study, the bovine embryo was used as a model to test the overall hypotheses that (1) canonical WNT signaling (i.e. WNT signaling mediated by nuclear localization of CTNNB1) is attenuated in the preimplantation embryo and (2) WNT can activate other signaling pathways in the embryo, as evaluated for activation of JNK. These hypotheses were evaluated in several experiments to characterize the developmental changes in expression of genes involved in WNT signaling, localization of CTNNB1 in blastomere nuclei and accumulation of phospho-JNK in the nucleus after WNT activation.

\section{Materials and methods}

\section{Embryo production}

Bovine embryos were produced in vitro from oocytes obtained from Bos (admixture of B. taurus and B. indicus) ovaries collected at a local abattoir. Procedures for oocyte recovery and maturation were as described elsewhere (Dobbs et al. 2013). After oocyte maturation, oocytes were fertilized for $8-10 \mathrm{~h}$ in groups of up to 300 oocytes with sperm pooled from three randomly selected $B$. taurus and $B$. indicus bulls using procedures described elsewhere (Denicol et al. 2014). Groups of 25-30 presumptive zygotes were placed in $50 \mu \mathrm{L}$ microdrops of SOF-BE2 (Kannampuzha-Francis et al. 2017) covered with mineral oil (Sigma-Aldrich) and cultured at $38.5^{\circ} \mathrm{C}$ in a humidified atmosphere of $5 \% \mathrm{O}_{2}$ and $5 \% \mathrm{CO}_{2}$ with the balance $\mathrm{N}_{2}$. Treatments were applied to cultured embryos by removing $5 \mu \mathrm{L}$ of culture medium and adding the treatment in a volume of $5 \mu \mathrm{L}$.

For immunofluorescence experiments, embryos were produced in vitro following procedures described above with a few modifications. Oocytes were harvested using BoviPRO oocyte washing medium (MOFA Global, Verona, WI, USA), and fertilization of matured oocytes was performed using IVF-TL (Parrish et al. 1986) (Caisson Laboratories, Logan, UT, USA) containing PHE $(80 \mu \mathrm{L}$ of $0.5 \mathrm{mM}$ penicillamine, $0.25 \mathrm{mM}$ hypotaurine and $25 \mu \mathrm{M}$ epinephrine in $0.9 \%(\mathrm{w} / \mathrm{v}) \mathrm{NaCl})$ as described by Ortega and coworkers (Ortega et al. 2016).

\section{Developmental changes in the expression of selected genes involved in WNT signaling (Experiment 1)}

To prepare pools of matured oocytes, cumulus-oocyte complexes (COCs) were harvested at the end of oocyte maturation $(20-22 \mathrm{~h})$. Cumulus cells were removed by vortexing for $5 \mathrm{~min}$ in HEPES-SOF medium (Denicol et al. 2014) containing $1000 \mathrm{U} / \mathrm{mL}$ hyaluronidase. Denuded oocytes were washed three times in Dulbecco's phosphate-buffered saline (DPBS) containing 1\% (w/v) polyvinylpyrrolidone (DPBS-PVP), incubated in $0.1 \%(\mathrm{w} / \mathrm{v})$ proteinase solution (protease from Streptomyces griseus; Sigma-Aldrich) in DPBS to remove the zona pellucida, washed three times in DPBSPVP and suspended in groups of 30 in $100 \mu \mathrm{L}$ extraction buffer from the PicoPure RNA Isolation kit (Applied Biosystems). Samples were stored at $-80^{\circ} \mathrm{C}$.

Embryos were produced by in vitro fertilization in 19 replicates. Embryos were harvested from culture drops at the following stages: 2-cell $(28-32 \mathrm{~h}$ after insemination (hpi)); 3-4 cell (44-48hpi); 5-8 cell (50-54hpi); 9-16 cell (72 hpi); morula (120 hpi) and blastocyst (168hpi). Embryos were collected, processed as for denuded oocytes to remove the zona pellucida, suspended in groups of 30 in $100 \mu \mathrm{L}$ extraction buffer from the PicoPure RNA Isolation kit (Applied Biosystems) and stored at $-80^{\circ} \mathrm{C}$. A separate pool of bulls was used for each replicate, resulting in a total of 19 different bulls.

Transcript abundance was examined for seven genes related to WNT signaling by quantitative real-time PCR (qPCR). Genes included two transcription factors (LEF1 and TCF7), two transcription factor inhibitors (AES and LOC505120 (GROUCHO-like)), two canonical WNT co-receptors (LRP5 and $L R P 6$ ) and a soluble inhibitor of canonical WNT signaling $(D K K 1)$ as well as three reference genes (GAPDH, SDHA and $Y W H A Z$ ). The reference genes were chosen because expression is stable over preimplantation development (Goossens et al. 2005), and we verified that developmental 
stage did not affect the expression of any of these three genes. Primers are listed in Supplementary Table 1 (see section on supplementary data given at the end of this article). Primers for $D K K 1, G A P D H, L R P 6, S D H A$ and YWHAZ were previously published (Goossens et al. 2005, Denicol et al. 2013), whereas those for AES, LEF1, LOC505120, LRP5 and TCF7 were designed using software from Integrated DNA Technologies (Coraville, lowa, USA). Primers were synthesized by Integrated DNA Technologies. All newly designed primer pairs were validated using cDNA from pools of Day 7 bovine blastocysts by generation of a standard curve (efficiency varied from 92.4 to $108.5 \%$ ), evaluation of melt curves and sequencing of PCR amplicons. Sequences were mapped to the B. taurus genome using the Basic Local Alignment Search Tool of the National Center for Biotechnology Information. All sequences aligned to the corresponding gene. RNA of pools of oocytes and embryos was extracted using the PicoPure RNA Isolation kit (Applied Biosystems) following the manufacturer's protocol. DNase treatment was performed using the QIAGEN DNase kit, and mRNA was reverse transcribed using the High Capacity cDNA Reverse Transcription Kit of Applied Biosystems. The qPCR utilized SsoFast EvaGreen Supermix reagent (Bio-Rad) and was performed with a Bio-Rad CFX96-Real-Time system using conditions described previously (Dobbs et al. 2013). Two technical replicates were prepared for each sample and the mean cycle threshold $\left(C_{T}\right)$ was calculated. Mean $C_{T}$ values greater than 35 were considered non-detectable and were assigned a value of 35 for statistical analysis.

A total of five biological replicates containing 30 oocytes or embryos each were subjected to qPCR. Data analyzed were $\Delta C_{\mathrm{T}}$ values, which were calculated by subtracting the geometric mean of the three reference genes from the mean $C_{\mathrm{T}}$ value of the sample. For graphical purposes, the relative transcript abundance was calculated as the $2^{\Delta C T}$. Therefore, abundance of each mRNA type is expressed relative to expression of reference genes.

Data were analyzed by least-squares analysis of variance using the GLM procedure of SAS for Windows, version 9.4 (SAS Institute Inc, Cary, NC, USA). Assumptions of analysis of variance were tested using the univariate procedure of SAS. Results are reported as least-squares means \pm S.E.M. The level of significance was $P<0.05$.

\section{Characteristics of the WNT signaling system in the morula and ICM and TE as revealed by RNA-Seq (Experiment 2)}

Data sets of the transcriptome of three pools of in vitroproduced morulae collected at Day 6 after insemination, and three pools of ICM and TE purified from in vitro-produced blastocysts at Day 8 after insemination, were examined for stage and cell type effects on expression of 80 genes involved in WNT signaling. Reads were mapped to Btau_4 (http:// genome.ucsc.edu/). Procedures and data for ICM and TE have been published previously (Ozawa et al. 2012), and raw data were deposited in the DDBJ Sequence Read Archive at http:// www.ddbj.nig.ac.jp/index-e.html (Submission DRA000504). The samples of morulae (100 per pool) were produced using the same procedures and in the same replicates of in vitro fertilization as for ICM and TE. Data were processed following the same bioinformatics methods as reported earlier (Ozawa et al. 2012). Details of the magnetic-activated cell sorting procedure used to separate ICM from TE were previously published (Ozawa \& Hansen 2011).

RNA-seq data were obtained using a SOLiD v4 sequencer (Applied Biosystems). Data on a subset of genes involved in WNT signaling were evaluated for treatment effects by leastsquares analysis of variance using the GLM procedure of SAS for Windows, version 9.4. The dependent variable was number of reads of the transcript, and the independent effect was cell type (morula, ICM and TE). The total transcript reads per sample was used as a covariate. Orthogonal contrasts were used to determine whether transcript abundance differed between morulae and blastocysts (morula vs ICM+TE) or between ICM and TE. Results are reported as least-squares means \pm S.E.M. The level of significance was $P<0.05$.

\section{Localization of total and active CTNNB1 in bovine embryos as determined by immunofluorescence (Experiments 3 and 4)}

Embryos produced in vitro were harvested at different stages of development using the same schedule as described earlier. Embryos were washed three times in cold DPBS-PVP, fixed in $4 \%(\mathrm{v} / \mathrm{v})$ paraformaldehyde in DBPS/PVP for $15 \mathrm{~min}$ and washed in DPBS/PVP three times. Immediately thereafter, embryos were incubated in permeabilization solution (DPBS containing $0.5 \%(\mathrm{v} / \mathrm{v})$ Triton X-100) for $30 \mathrm{~min}$ at room temperature, followed by incubation for $1 \mathrm{~h}$ in blocking buffer (DPBS containing 5\% (w/v) bovine serum albumin (BSA)). Embryos were then incubated overnight at $4^{\circ} \mathrm{C}$ with $1 \mu \mathrm{g} /$ $\mathrm{mL}$ of primary antibody in antibody buffer (DPBS containing $0.1 \%(\mathrm{v} / \mathrm{v})$ Tween 20 and $1 \%$ BSA (w/v)). For the detection of total CTNNB1 (Experiment 3), rabbit polyclonal antihuman CTNNB1 antibody (Abcam) was used. For detection of active CTNNB1 (Experiment 4), rabbit polyclonal antihuman non-phospho (active) CTNNB1 antibody (Ser33/37/ Thr41; Cell Signaling Technology) was used, and for negative control, primary antibody was replaced with the same concentration of rabbit IgG. Details of all primary antibodies are in Supplementary Table 2. After three washes in washing buffer (DPBS containing 0.1\% (v/v) Tween 20 and 0.1\% BSA $(\mathrm{w} / \mathrm{v}))$, oocytes and embryos were incubated with $1 \mu \mathrm{g} / \mathrm{mL}$ goat anti-rabbit IgG conjugated with Alexa Fluor 555 (Life Technologies) for $1 \mathrm{~h}$ at room temperature in the darkness. Primary and secondary antibodies were diluted in antibody buffer. Nuclear labeling was achieved by incubation with $1 \mu \mathrm{g} / \mathrm{mL}$ Hoechst 33342 (Sigma-Aldrich) for $15 \mathrm{~min}$ at room temperature. Embryos were finally rinsed in DPBS/PVP and placed on a slide containing SlowFade Gold anti-fade reagent (Life Technologies), covered with a coverslip and observed with a $40 \times$ objective using a Zeiss Axioplan 2 epifluorescence microscope (Zeiss) and Zeiss filter sets 02 (4,6-diamidino-2phenylindole (DAPI)) and 04 (rhodamine).

Digital images were acquired using AxioVision software (Zeiss) and a high-resolution black and white Zeiss AxioCam MRm digital camera. For Experiment 3, evaluation of total CTNNB1 was replicated 7 times with a total of 450 embryos. 
For Experiment 4, evaluation of active CTNNB1 was replicated 5 times with a total of 417 embryos.

\section{Changes in immunoreactive active CTNNB1 in embryos after activation of canonical WNT signaling (Experiments 5-8)}

For Experiment 5, in vitro-produced embryos were cultured in drops as described previously. Culture drops were randomly assigned to stage and treatments. Developmental stages included 3-4 cell (44-48 hpi), 5-8 cell (50-54 hpi), 9-16 cell (72 hpi) and compact morula (120 hpi). At the corresponding time for each developmental stage, $5 \mu \mathrm{L}$ of SOF-BE2 in the culture drop were replaced by either $5 \mu \mathrm{L}$ GSK3 inhibitor (CHIR$99021 \mathrm{HCL}$; Tocris Bioscience, Bristol, UK), $5 \mu \mathrm{L}$ of the nuclear export inhibitor leptomycin (Sigma), $5 \mu \mathrm{L}$ leptomycin + GSK3 inhibitor or $5 \mu \mathrm{L}$ vehicle (SOF-BE2 containing $0.04 \%(\mathrm{v} / \mathrm{v})$ ethanol). Final concentrations were $10 \mu \mathrm{M}$ for the GSK3 inhibitor and $22 \mathrm{ng} / \mathrm{mL}$ for leptomycin. After $30 \mathrm{~min}$ of treatment while embryos were maintained in culture conditions (30 min was chosen because leptomycin B increases nuclear NFkB p65 in HeLa cells at this time (Wolff et al. 1997)), embryos were fixed and labeling for immunofluorescence was carried out as described earlier using antibody against non-phospho (active) CTNNB1 or the corresponding rabbit IgG. A total of 191 embryos were evaluated.

For Experiment 6, canonical WNT signaling in 5-8-cell embryos and morulae was stimulated by addition of final concentrations of either $100 \mathrm{ng} / \mathrm{mL}$ human recombinant WNT1 (Sigma-Aldrich; 99\% identical amino acid sequence to bovine WNT1), $0.7 \mu \mathrm{M}$ of the WNT agonist 2-amino-4(3,4-(methylenedioxy)benzylamino)-6-(3-methoxyphenyl) pyrimidine (AMBMP, Sigma-Aldrich) or SOF-BE2 containing $0.1 \%(\mathrm{v} / \mathrm{v})$ DMSO (vehicle). Embryos were harvested 1, 6 and $24 \mathrm{~h}$ after treatment and were analyzed by immunofluorescence for nuclear active CTNNB1 ( $n=36$ embryos). For Experiment 7 , compact morulae were treated with $0.7 \mu \mathrm{M}$ AMBMP or vehicle at Day 5 after insemination. Blastocysts were harvested $48 \mathrm{~h}$ later for the assessment of nuclear active CTNNB1 $(n=78$ embryos). For Experiment 8, embryos were treated with $10 \mu \mathrm{M}$ GSK3 inhibitor (CHIR-99021) on Day 6 after insemination or were used as a control group that received an equivalent amount of vehicle (SOF-BE2 containing 0.04\% (v/v) ethanol). Blastocysts were harvested $24 \mathrm{~h}$ after treatment for the assessment of nuclear active CTNNB1 ( $n=15$ embryos).

\section{Localization of active CTNNB1 in mouse and bovine embryos as evaluated by confocal microscopy (Experiment 9 and 10)}

For Experiment 9, cryopreserved 5-8-cell mouse embryos $\left(\mathrm{B}_{6} \mathrm{C}_{3} \mathrm{~F}_{1} \times \mathrm{B}_{6} \mathrm{D}_{2} \mathrm{~F}_{1}\right)$ were obtained from Embryotech Laboratories (Haverhill, MA, USA) and thawed following the supplier's instructions. Embryos were washed with HEPES-TALP and incubated in $50 \mu \mathrm{L}$ oil-covered microdrops of EmbryoMax $\mathrm{KSOM}$ medium with amino acids (EMD Millipore) for $3 \mathrm{~h}$ at $38.5^{\circ} \mathrm{C}$ in a humidified atmosphere of $5 \% \mathrm{CO}_{2}$ and $5 \% \mathrm{O}_{2}$. The 5-8-cell embryos were fixed in $10 \%(\mathrm{v} / \mathrm{v})$ formalin for $30 \mathrm{~min}$, permeabilized in $2.5 \%$ (v/v) Tween 20 in DPBS for $20 \mathrm{~min}$, blocked with DPBS containing $5 \%(\mathrm{w} / \mathrm{v})$ BSA for $1 \mathrm{~h}$ and incubated overnight with $1 \mu \mathrm{g} / \mathrm{mL}$ purified mouse monoclonal IgG against active CTNNB1 (anti-active-CTNNB1 (anti-ABC) clone 8E7; Millipore) at $4{ }^{\circ} \mathrm{C}$. After sequential washes with DPBS containing $0.1 \%(\mathrm{w} / \mathrm{v})$ BSA and $0.1 \%(\mathrm{v} / \mathrm{v})$ Tween 20, embryos were incubated in affinity-purified goat anti-mouse IgG coupled to fluorescein isothiocyanate (FITC; Abcam) for $1 \mathrm{~h}$ at room temperature, followed by 5 -min incubation in $1 \mu \mathrm{g} / \mathrm{mL}$ Hoechst 33342. Embryos were suspended in $10 \mu \mathrm{L}$ drops of ProLong Gold anti-fade mounting medium (Thermo Fisher Scientific) in chamber slides. Embryos $(n=5)$ were observed using a spinning disk confocal scanner mounted to an Olympus DSU-IX81 inverted fluorescent microscope. Digital images were captured with a $60 \times$ objective and DAPI and FITC filter sets, using an attached Hamamatsu C4742-12AG monochrome CCD camera.

For Experiment 10, bovine embryos were produced in vitro and harvested at the morula stage on Day 5 and blastocyst stage on Day 7 after insemination. Labeling of active CTNNB1 was performed following same procedure and antibody as for Experiment 4 except that embryos were suspended in $10 \mu \mathrm{L}$ drops of ProLong Gold anti-fade mounting medium (Thermo Fisher Scientific) in chamber slides. Embryos $(n=4)$ were observed and images were captured using the spinning disk confocal scanner and camera mentioned previously, with 40 or $60 \times$ objectives and DAPI and Texas Red filter sets.
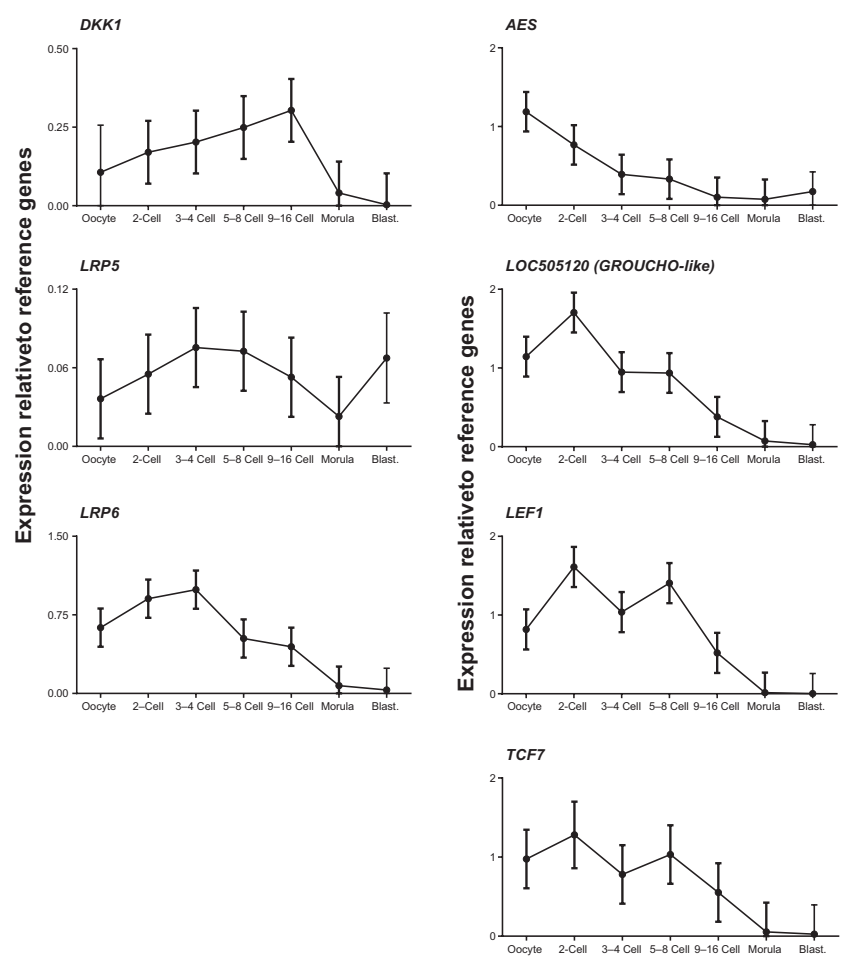

Figure 1 Developmental changes in expression of selected genes involved in WNT signaling for bovine embryos produced in vitro (Experiment 1). Expression was assessed by qPCR. Expression of each gene was affected by stage of development $(P=0.004$ for $L R P 5$ and $P<0.0001$ for the other genes). Data are presented as least-squares means \pm S.E.M. of results from 5 replicates. Blast, blastocyst (168 hpi). 


\section{Nuclear localization of CTNNB1 in bovine embryonic fibroblast cells after activation of canonical WNT signaling (Experiment 11)}

Cells of the bovine embryonic fibroblast (BEF) cell line developed in our laboratory (Ozawa et al. 2012) were studied to verify nuclear labeling of non-phospho (active) CTNNB1 in non-embryonic cells. Cells were cultured with Dulbecco's modified Eagle's Medium (Gibco, Thermo Fisher Scientific) containing $10 \%(\mathrm{v} / \mathrm{v})$ fetal bovine serum and $1 \%(\mathrm{v} / \mathrm{v})$ antibiotic-antimycotic $(10,000 \mathrm{units} / \mathrm{mL}$ penicillin, $10 \mathrm{mg} / \mathrm{mL}$ streptomycin and $25 \mu \mathrm{g} / \mathrm{mL}$ amphotericin B; Sigma-Aldrich). Cells were initially cultured in cell culture flasks (Corning)

Table 1 Effect of stage of development and cell lineage (inner cell mass (ICM) vs trophectoderm (TE)) on expression of genes involved in WNT signaling for Day 6 morula and Day 8 bovine blastocysts produced in vitro. ${ }^{\mathrm{a}}$

\begin{tabular}{|c|c|c|c|c|c|}
\hline \multirow[b]{2}{*}{ Gene } & \multicolumn{3}{|c|}{ Number of reads } & \multicolumn{2}{|c|}{$P$ value } \\
\hline & Morula & ICM & TE & Morula vs (ICM+TE) & ICM vs TE \\
\hline \multicolumn{6}{|l|}{ WNTs ${ }^{b}$} \\
\hline WNT2 & 18.49 & 15.19 & 17.66 & 0.778 & 0.784 \\
\hline WNT2B & 22.00 & 21.00 & 50.67 & 0.079 & 0.952 \\
\hline WNT6 & 0.20 & 2.96 & 14.51 & $<0.0001$ & $<0.0001$ \\
\hline WNT8A & 5.82 & 0.27 & 1.12 & 0.079 & 0.664 \\
\hline WNT10A & 395.0 & 468.0 & 652.7 & 0.068 & 0.548 \\
\hline WNT11 & 101.0 & 91.33 & 119.7 & 0.376 & 0.745 \\
\hline WNT16 & 4.09 & 23.65 & 12.26 & 0.236 & 0.409 \\
\hline \multicolumn{6}{|l|}{ WNT processing } \\
\hline PORCN & 196.97 & 213.19 & 450.17 & 0.016 & 0.004 \\
\hline \multicolumn{6}{|c|}{ Frizzled receptors and LRP co-receptors ${ }^{c}$} \\
\hline FZD1 & 145.00 & 82.33 & 140.00 & 0.159 & 0.016 \\
\hline FZD3 & 9.62 & 3.43 & 5.29 & 0.098 & 0.585 \\
\hline FZD6 & 62.29 & 108.59 & 132.79 & 0.032 & 0.367 \\
\hline FZD7 & 31.21 & 18.56 & 55.90 & 0.231 & 0.001 \\
\hline FZD8 & 91.00 & 50.49 & 58.17 & 0.385 & 0.877 \\
\hline FZD10 & 73.33 & 59.33 & 75.33 & 0.539 & 0.415 \\
\hline LRP6 & 302.90 & 264.38 & 412.72 & 0.390 & 0.024 \\
\hline \multicolumn{6}{|c|}{ Proteins involved in canonical signaling ${ }^{\mathrm{d}}$} \\
\hline$A P C$ & 14.43 & 12.47 & 19.77 & 0.247 & 0.006 \\
\hline AXIN1 & 30.56 & 18.00 & 31.44 & 0.450 & 0.186 \\
\hline$C N B P$ & 11.79 & 9.83 & 9.38 & 0.469 & 0.901 \\
\hline CTNNB1 & 584.6 & 5897.4 & 6838.01 & 0.673 & 0.540 \\
\hline DVL2 & 9.89 & 4.84 & 6.60 & 0.315 & 0.717 \\
\hline DVL3 & 49.99 & 37.32 & 66.36 & 0.913 & 0.203 \\
\hline GSK3B & 1144.6 & 549.73 & 720.33 & 0.060 & 0.539 \\
\hline \multicolumn{6}{|l|}{ Transcription factors ${ }^{\mathrm{e}}$} \\
\hline$L E F 1$ & 61.55 & 1.64 & 3.14 & 0.096 & 0.968 \\
\hline TCF7L1 & 12.16 & 16.53 & 10.31 & 0.859 & 0.486 \\
\hline TCF7L2 & 556.98 & 211.86 & 116.16 & 0.003 & 0.339 \\
\hline \multicolumn{6}{|c|}{ Transcription factors inhibitors ${ }^{f}$} \\
\hline$A E S$ & 48.68 & 136.79 & 181.86 & 0.04 & 0.402 \\
\hline TLE3 & 17.67 & 89.67 & 122.00 & 0.154 & 0.187 \\
\hline \multicolumn{6}{|l|}{ R-spondin signalingg } \\
\hline LGR4 & 166.23 & 60.65 & 102.46 & 0.032 & 0.289 \\
\hline LOC $100337123^{\mathrm{h}}$ & 11.74 & 3.25 & 5.67 & 0.002 & 0.174 \\
\hline RSPO 1 & 202.67 & 187.00 & 211.00 & 0.703 & 0.749 \\
\hline RSPO2 & 11.91 & 0.62 & 4.04 & 0.118 & 0.514 \\
\hline RSPO3 & 1925.6 & 643.08 & 301.03 & 0.019 & 0.540 \\
\hline \multicolumn{6}{|c|}{ Other soluble WNT regulatory proteinsi } \\
\hline$D K K 1$ & 15.71 & 3.22 & 1.06 & 0.056 & 0.761 \\
\hline NDP & 1498.1 & 1510.6 & 1779.3 & 0.670 & 0.530 \\
\hline SFRP1 & 124.75 & 48.81 & 143.11 & 0.145 & 0.006 \\
\hline SFRP2 & 61.00 & 16.00 & 25.67 & 0.700 & 0.236 \\
\hline SFRP3 & 63.47 & 23.03 & 16.83 & 0.236 & 0.882 \\
\hline SFRP4 & 31.67 & 25.67 & 38.67 & 0.127 & 0.393 \\
\hline WIF1 & 96.78 & 30.92 & 33.30 & 0.040 & 0.937 \\
\hline \multicolumn{6}{|c|}{ Other WNT signaling proteins $\mathrm{s}^{\mathrm{j}}$} \\
\hline DACT2 & 49.56 & 41.19 & 43.25 & 0.367 & 0.830 \\
\hline KREMEN1 & 53.14 & 9.67 & 15.87 & 0.011 & 0.643 \\
\hline$R Y K$ & 97.14 & 46.14 & 79.40 & 0.172 & 0.265 \\
\hline
\end{tabular}

${ }^{a}$ Data are least-squares means of number of reads. ${ }^{b}$ The following genes had $<5$ reads: WNT1, WNT3, WNT3A, WNT4, WNT5A, WNT5B, WNT7A, LOC100337066 (WNT7B paralog), WNT8B, WNT9A, WNT9B and WNT10B. 'The following genes had <5 reads: FZD2, FZD4, FZD5,

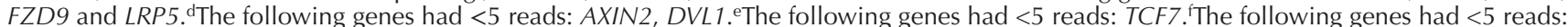
LOC505120 (GROUCHO ortholog), TLE1, TLE2, TLE4 and TLE6. ${ }^{\mathrm{g} T h e}$ following genes had $<5$ reads: LGR5, LGR6 and RSPO5. ${ }^{\mathrm{h}}$ RSPO3 like. The following genes had $<5$ reads: DKK4 and SFRP5. The following genes had $<5$ reads: ANKRD6, DACT1, DACT3, FRAT1, KREMEN2, NKD2, VANGL1 and VANGL2. 
2 cell

3-4 cell

5-8 cell

9-16 cell

Morula

Blastocyst
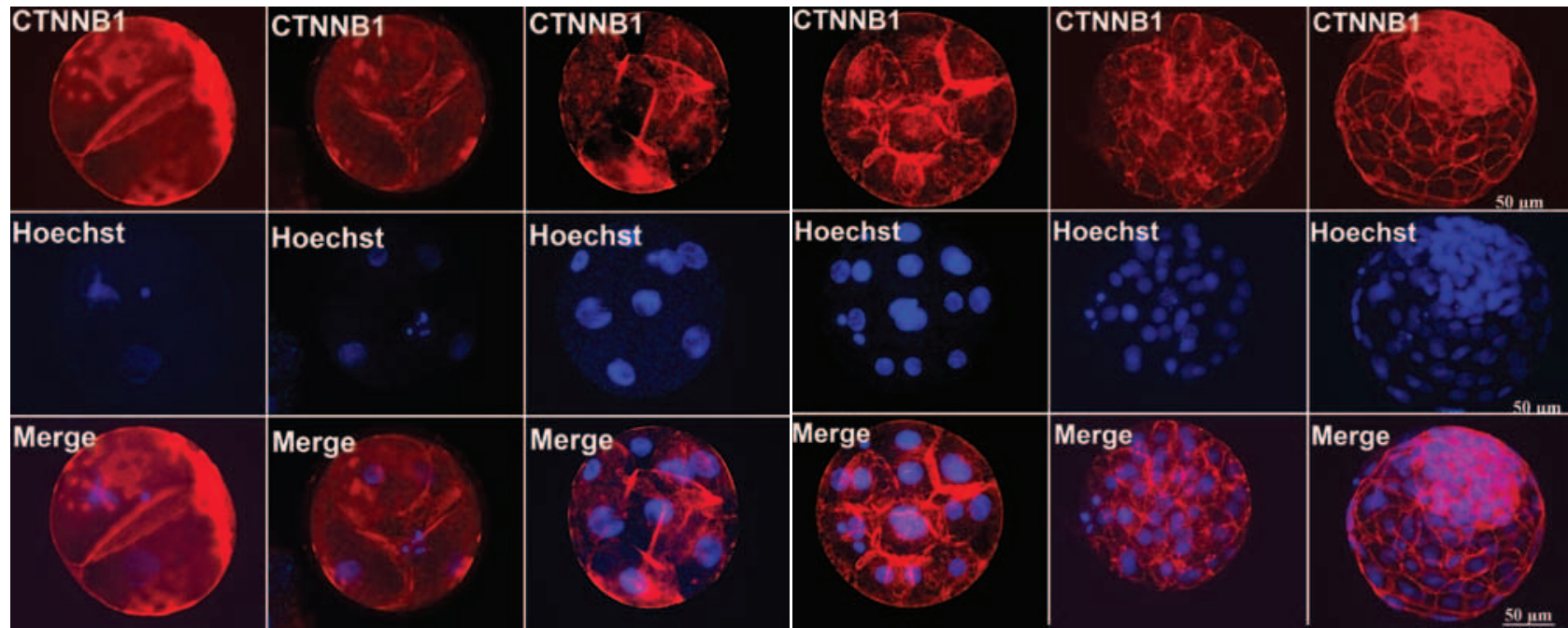

Figure 2 Representative examples of localization of immunoreactive CTNNB1 at various stages of preimplantation development of bovine embryos produced in vitro (Experiment 3). Embryos were labeled with antibody to CTNNB1 (red) and DNA (blue). The total number of embryos evaluated was 450 .

at $38.5^{\circ} \mathrm{C}$ in a humidified atmosphere of $5 \% \mathrm{CO}_{2}$. At $90 \%$ confluency, cells were trypsinized $(0.25 \%(\mathrm{w} / \mathrm{v})$ trypsin, Life Technologies), mixed with an equal volume of culture medium, centrifuged for $10 \mathrm{~min}$ at $1750 \mathrm{~g}$, resuspended in culture medium and counted (Automated Cell Counter, Bio-Rad). Cells were seeded in 8-chamber slides (Sigma-Aldrich) at a density of 10,000 cells/well and were allowed to adhere overnight in culture medium. Culture medium containing treatments were used to replace medium. Treatments included $10 \mu \mathrm{M}$ GSK3 inhibitor (CHIR-99021), 0.7 $\mu$ M AMBMP or vehicle $(0.5 \%(\mathrm{v} / \mathrm{v})$ DMSO). Concentrations were chosen based on the effect of these molecules in other studies (Denicol et al. 2013, Lappas 2014). Fixation and immunolabeling of cells were performed
$24 \mathrm{~h}$ after treatment using $4 \%$ paraformaldehyde for $20 \mathrm{~min}$, followed by permeabilization with DPBS containing $0.5 \%$ $(\mathrm{v} / \mathrm{v})$ Triton X-100 during $30 \mathrm{~min}$ and blocking for $1 \mathrm{~h}$ with DPBS containing 5\% (w/v) BSA. Incubation with primary antibody (rabbit anti-human polyclonal non-phospho (active) CTNNB1 (Ser33/37/Thr41); Cell Signaling Technology) or rabbit IgG proceeded overnight at $4{ }^{\circ} \mathrm{C}$. Incubation with goat anti-rabbit IgG conjugated with Alexa Fluor 555 proceeded for $1 \mathrm{~h}$, followed by DNA labeling using Hoechst 33342. Cells were observed and images were captured following methods described for mouse embryos; DAPI and Texas Red fluorescence filters were used. Image analyses consisted of quantification of proportion of cells depicting nuclear CTNNB1.

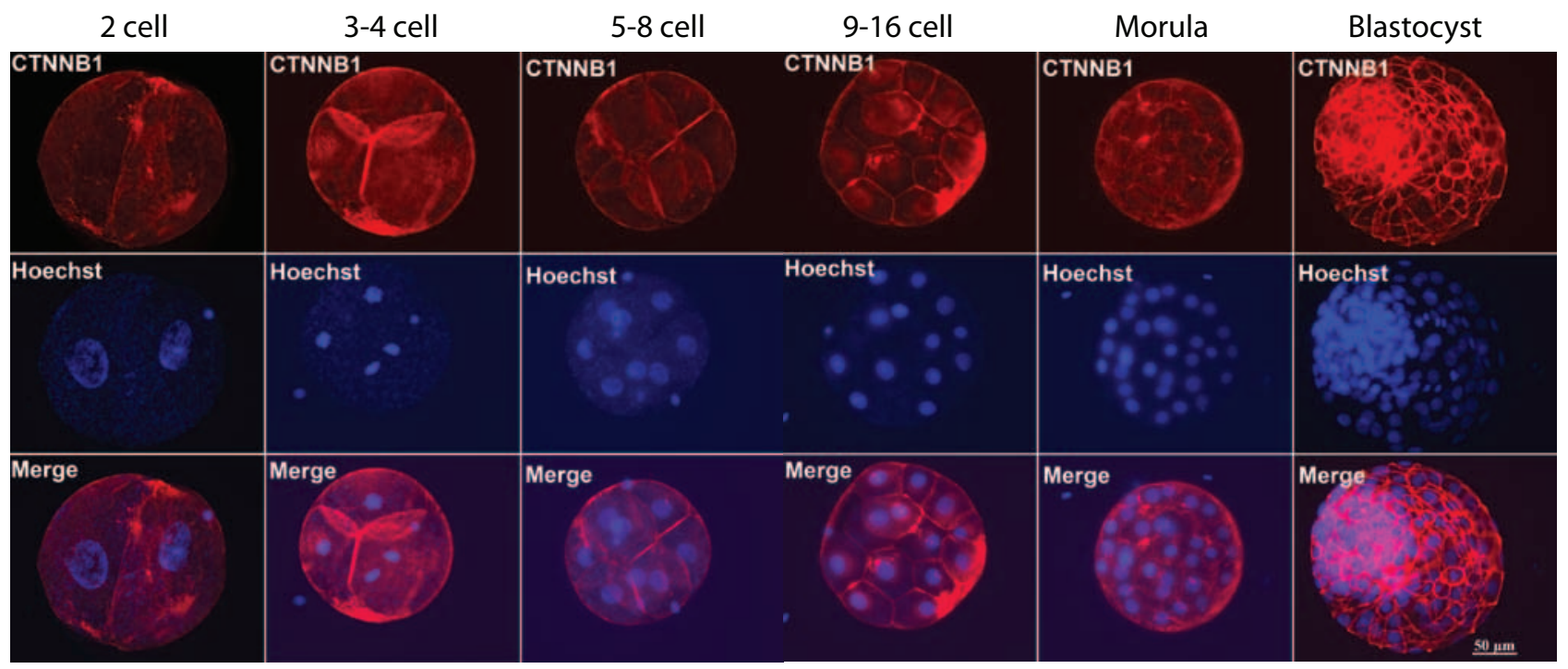

Figure 3 Representative examples of localization of immunoreactive non-phospho (active) CTNNB1 during preimplantation development of bovine embryos produced in vitro (Experiment 4). Embryos were labeled with antibody to non-phospho (active) CTNNB1 (red) and DNA (blue). A total of 417 embryos was evaluated. 


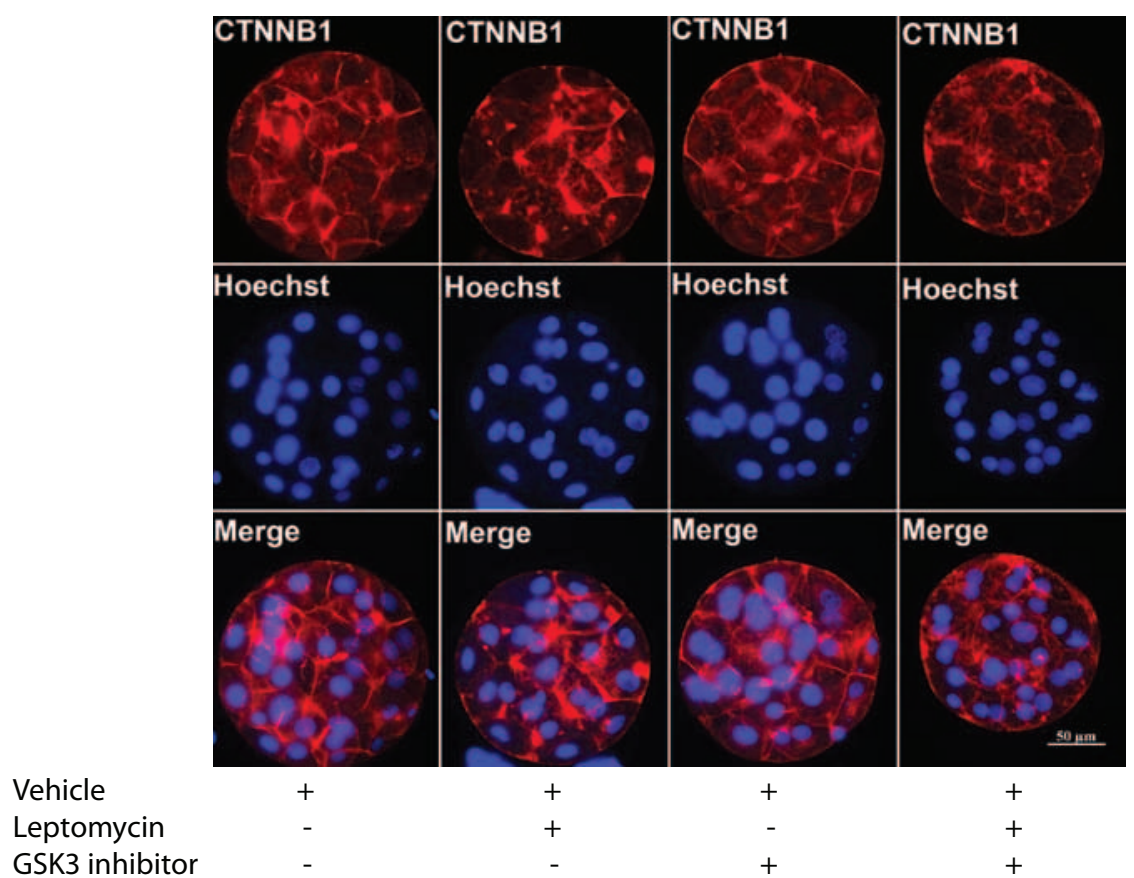

Figure 4 Lack of localization of active CTNNB1 in the nucleus of in vitro-produced bovine embryos after activation of canonical WNT signaling with the GSK3 inhibitor (Experiment 5). Leptomycin was added to reduce nuclear export of CTNNB1. Shown are representative images of individual embryos labeled with antibody to non-phospho (active) CTNNB1 (red) and DNA (blue) treated at the 9-16-cell stage and harvested $24 \mathrm{~h}$ after stimulation. Similar results were seen for embryos treated at other stages of development (total number of embryos examined $=191$ ).
A total of 41 images were analyzed. The proportion of cells showing nuclear localization of active CTNNB1 was analyzed by logistic regression using the LOGISTIC procedure of SAS for Windows, version 9.4 (SAS Institute Inc.) including treatment as a fixed effect. The PDIFF means separation test was used to determine which treatments differed from control cells. The level of significance was $P<0.05$.

\section{Non-canonical WNT signaling mediated by phosphorylation of JNK (i.e. MAPK8) by WNT11 in bovine blastocysts (Experiments 12-14)}

Experiment 12 was performed to determine whether WNTs could activate one component of the planar cell polarity pathway in bovine embryos. Embryos were produced in vitro as described. At Day 7 after insemination, culture drops were randomly assigned to treatments. In each culture drop, $5 \mu \mathrm{L}$ of SOF-BE2 were replaced by either $5 \mu \mathrm{L}$ human recombinant WNT11 (R\&D Systems; 98\% amino acid sequence identity with bovine WNT11) or $5 \mu \mathrm{L}$ vehicle (SOF-BE2 containing $0.01 \%(\mathrm{w} / \mathrm{v}) \mathrm{BSA}$ (in addition to BSA included in SOF-BE2 formulation)). Final concentrations of WNT11 were $0.5,1$ and $2.5 \mu \mathrm{g} / \mathrm{mL}$. Blastocysts were harvested $6 \mathrm{~h}$ after treatment and fixed in $4 \%(\mathrm{v} / \mathrm{v})$ paraformaldehyde. Immunolabeling was performed as described for CTNNB1 except that the primary antibody was $1 \mu \mathrm{g} / \mathrm{mL}$ anti-phospho-JNK ((Thr183/Tyr185 and Thr221/Tyr223), Millipore) and $1 \mu \mathrm{g} /$ $\mathrm{mL}$ rabbit IgG served as a negative control. Note that the phosphorylation site is conserved among human, mouse and bovine and that the amino acid sequence identity between these species is $97-99 \%$. Embryos were then incubated with $1 \mu \mathrm{g} / \mathrm{mL}$ goat anti-rabbit IgG conjugated with Alexa Fluor 555 (Life Technologies), and nuclear labeling was performed using Hoechst 33342. Embryos were evaluated using a Zeiss Axioplan 2 epifluorescence microscope as described earlier. Quantification of intensity of labeling with antibody was performed using ImageJ software (U.S. National Institutes of Health, Berthesda, MD, USA; version 1.70_02). Total immunoreactive phospho-JNK was measured as follows: after selection of the area encompassing the entire embryo, the mean intensity was obtained using the Measure Analysis feature and the background intensity was obtained from the area surrounding the embryo. The latter was subtracted from the embryo intensity before statistical analysis. A total of 49 embryos were analyzed. Data were analyzed by leastsquares analysis of variance using the PROC GLM procedure of SAS for Windows, version 9.4 (SAS Institute Inc.) including WNT11 concentration as a fixed effect. Differences between individual concentrations of WNT11 and control embryos were assessed using the PDIFF mean separation test of SAS.

Experiment 13 was performed to test whether WNT11 affected the competence of embryos to develop to the blastocyst stage and allocation of blastocyst blastomeres to TE and ICM. Treatments (vehicle and $2.5 \mu \mathrm{g} / \mathrm{mL}$ WNT11) were applied at Day 5 after fertilization as described previously. Blastocyst development was assessed on Day 7 after fertilization, and blastocysts with clearly delineated blastocoels were harvested, fixed, permeabilized and blocked as described previously. Trophectoderm cells were identified by localization of a transcription factor crucial for differentiation of TE (caudal type homeobox 2 (CDX2); (Berg et al. 2011)). Labeling was achieved by sequential incubation with mouse anti-human polyclonal CDX2 antibody ready to use (Biogenex, Fremont, CA, USA) and $1 \mu \mathrm{g} / \mathrm{mL}$ goat anti-mouse IgG conjugated with FITC (Abcam). Total number of cells was determined by counting DNAlabeled nuclei by labeling with $1 \mu \mathrm{g} / \mathrm{mL}$ Hoechst 33342 after immunolabeling for CDX2. Number of ICM was calculated as the difference between total cells and TE. The experiment was performed in 5 replicates with a total of 484 COCs and semen from 13 different bulls. Blastocyst cell number was evaluated for 74 embryos, and data were analyzed for the effect of treatment using Proc Glimmix of SAS for Windows, version 9.4 (SAS 
A Vehicle
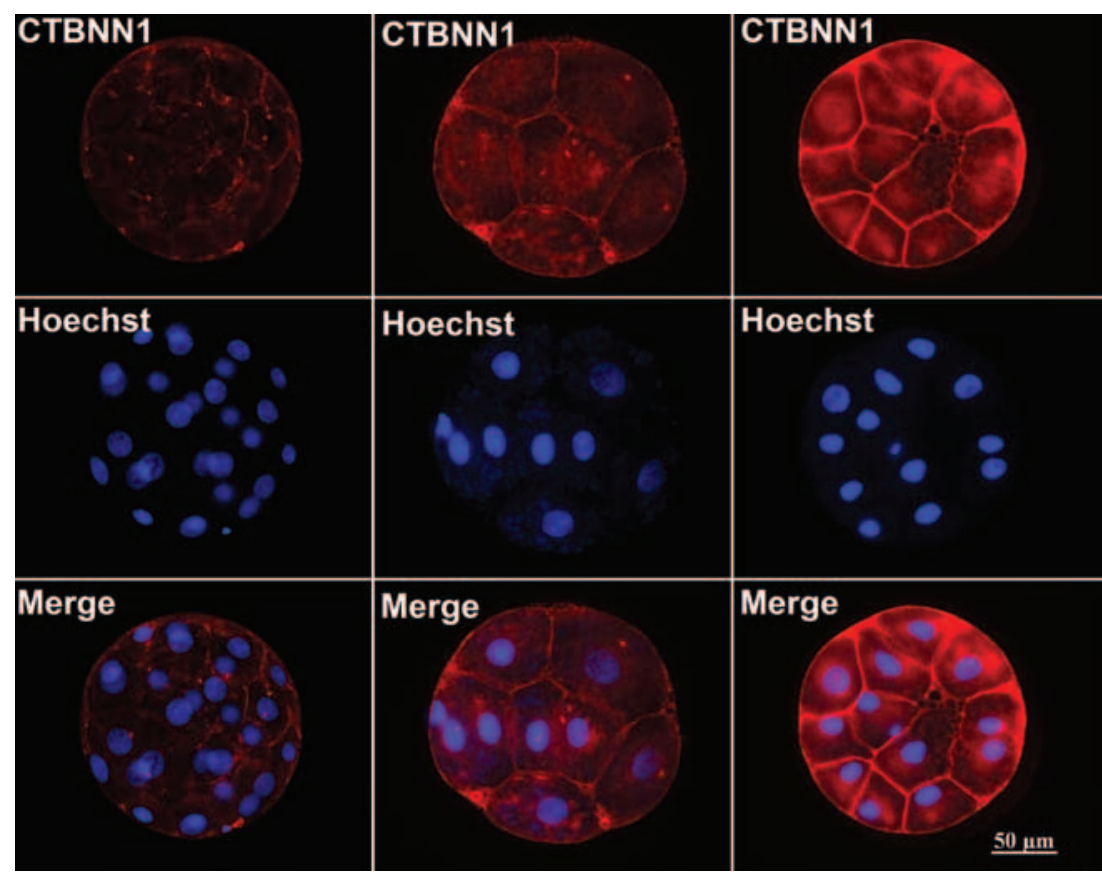

B
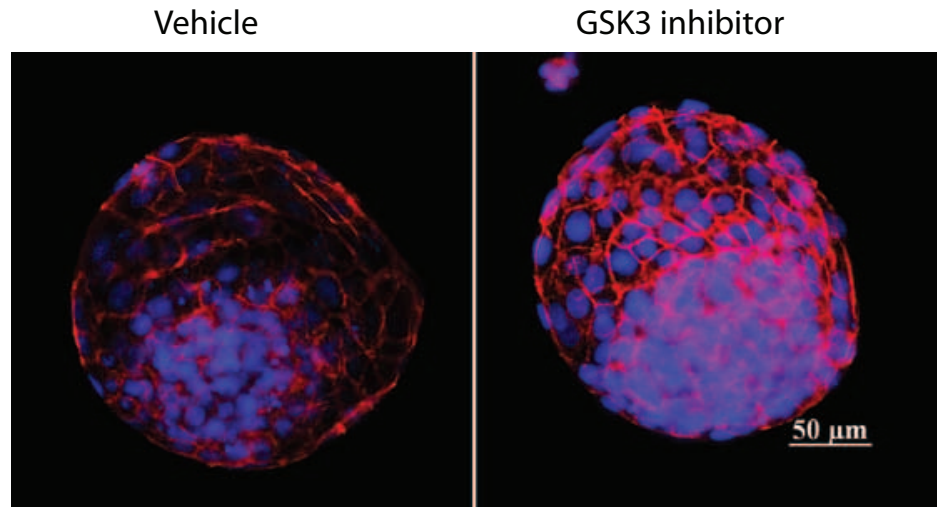

WNT1

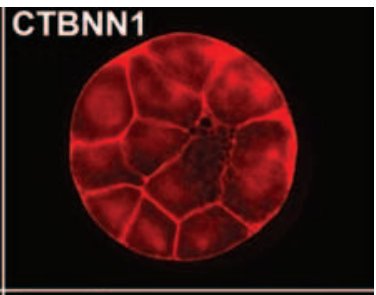

Hoechst

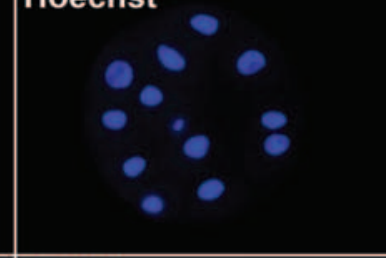

Merge
Institute Inc.). Each embryo was considered an observation, and development $(0=$ not developed to blastocyst; $1=$ developed to blastocyst) was considered a binary variable. Results are presented as least-squares means \pm S.E.M.

\section{Results}

\section{Developmental changes in expression of selected genes related to WNT signaling for embryos produced in vitro (Experiment 1)}

Results on the expression of seven genes related to WNT signaling in embryos produced in vitro are shown in Fig. 1. Expression of each gene was affected by stage of development $(P=0.004$ for $L R P 5$ and $P<0.0001$ for the other genes). There were several distinct developmental patterns in gene expression. The first was a continuous decline in transcript abundance from the oocyte to the morula stage. Only AES showed this pattern and, for this gene, there was a slight increase in transcript abundance by the blastocyst stage. A second pattern, shown for $D K K 1$, was a continuous increase from the oocyte stage to the 9-16 cell stage followed by a decline in transcript abundance. For the other five genes, there was a slight increase in transcript abundance from the oocyte to the 2-cell or 4-cell stage followed by a decline in transcript abundance after the 2-cell, 4-cell or 5-8-cell stage. Transcripts for two genes, DKK1 and $L E F 1$, were not detectable at the blastocyst stage.

\section{Characteristics of the WNT signaling system in the morula and ICM and TE of in vitro-produced embryos as revealed by RNA-Seq (Experiment 2)}

A RNA-Seq database of the transcriptomes of in vitroproduced Day 6 morulae and isolated TE and ICM of Day 8 blastocysts (Ozawa et al. 2012) was assessed for the expression of 80 genes associated with 

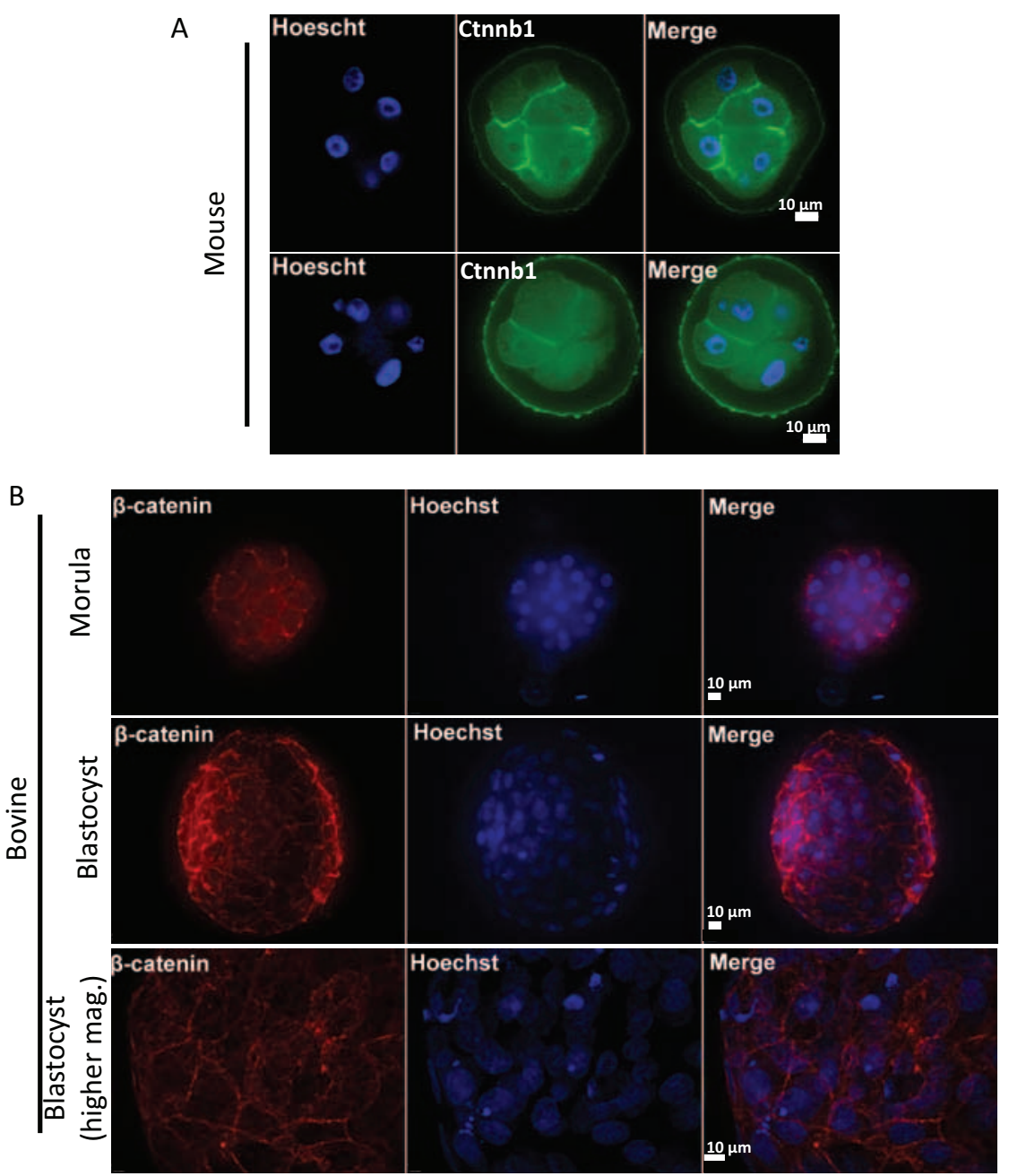

Figure 6 Localization of active CTNNB1 in mouse and bovine embryos by confocal microscopy. Shown in panel A (Experiment 10) are images of 2 individual 5-cell mouse embryos labeled with non-phospho (active) CTNNB1 (green) and Hoechst (blue). A total of 5 embryos were examined. Shown in panel B (Experiment 11) are representative confocal images of bovine embryos at the morula stage (top), at the blastocyst stage (middle), and at the blastocyst stage captured with higher magnification (bottom). A total of 4 embryos were examined.
WNT signaling. Genes were considered expressed if the average number of reads was $\geq 5$. Results are summarized in Table 1.

Only 7 of 19 WNT genes were expressed with the remaining $12 W N T$ genes having $<5$ reads or being not detected. Of the 7 WNT that were expressed, only one, WNT6, varied in expression between groups. Expression was higher for TE than ICM or morula. A key gene involved in posttranslational modification of WNTs, PORCN, was highly expressed, and transcript abundance was higher for TE than morula or ICM.

A total of 6 of 10 FZD receptor genes were expressed in the morula or blastocyst. Expression of $F Z D 1$ and FZD7 was lower for ICM than that for TE. In contrast, expression of FZD6 was higher for both ICM and TE of the blastocyst than that for the morula. The FZD co-receptor gene, $L R P 6$, was abundantly expressed but number of reads for $L R P 5$ was $<5$.

Among the genes involved in canonical WNT signaling that were expressed were CTNNB1 and genes involved in the CTNNB1 destruction complex $(A P C$, AXIN1 and GSK3B). DVL1, which acts to bind FZD proteins and transmit information about WNT binding, was not considered expressed ( $<5$ reads). However, two other disheveled genes (DVL2 and DVL3) were expressed. The only gene involved in CTNNB1 metabolism that varied with stage of development was $A P C$, which was expressed more in TE than ICM.

Expression of the two WNT-regulated transcription factor genes, TCF7 and LEF1, was low. In addition, expression of TCF7L1 was relatively low in both morula and blastocysts. In contrast, TCF7L2 was highly expressed although expression declined from the morula to the blastocyst stage for both ICM and TE. In contrast, the transcription factor inhibitor, AES, increased in transcript abundance from the morula to blastocyst stage for both ICM and TE.

Expression was also examined for several genes that can promote or antagonize canonical WNT signaling. Among such genes that were affected by developmental stage, were the WNT stimulatory molecule, RSPO3 and one of its receptors, $L G R 4$. Expression of both genes was significantly lower for ICM and TE of the blastocyst than for morula. Two antagonists of canonical WNT signaling also declined from the morula to blastocyst stage, DKK1 
and WIF1. KREMEN1, which can function as a DKK1 receptor, was also reduced in expression for ICM and TE of the blastocyst as compared to the morula.

Note that the pattern of gene expression was generally consistent with the earlier experiment (Fig. 1). In the first experiment, expression of six genes declined from the Day 5 morula to the Day 7 blastocyst. A similar decline occurred from the Day 6 morula to Day 8 blastocyst for $D K K 1$ and LEF1. LRP6 did not change in expression, and LOC505120 and TCF7 were not detected by RNAseq and LRP5 was barely detectable. There was one gene whose expression increased very slightly from the morula to blastocyst stage in the first experiment, $A E S$, and a larger increase was observed when comparing the Day 6 morula to Day 8 blastocyst.

\section{Localization of total and active CTNNB1 in bovine preimplantation embryos as determined by immunofluorescence (Experiments 3 and 4)}

Expression of genes coding for molecules involved in WNT signaling was indicative that canonical WNT
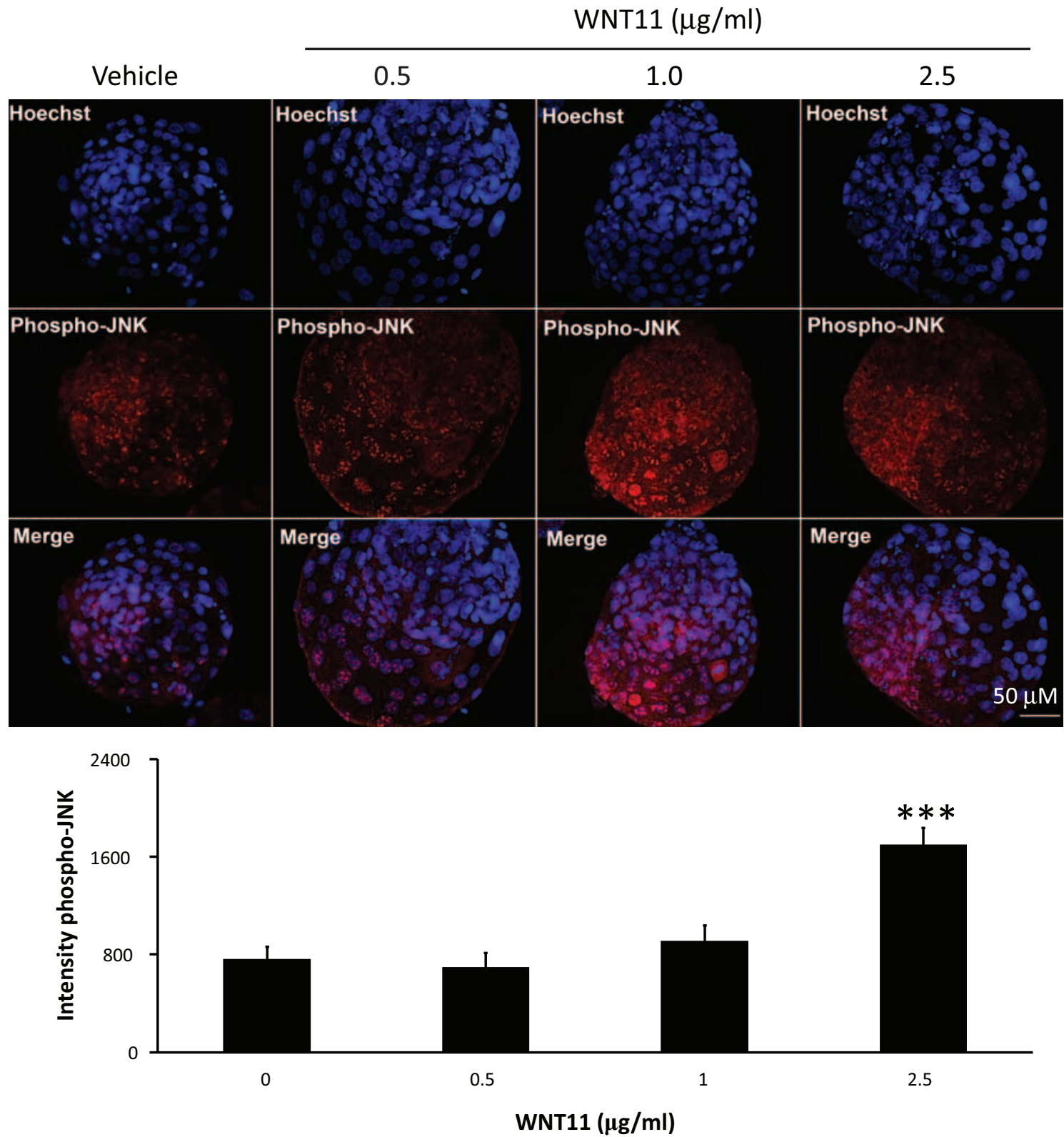

Figure 7 Immunoreactive phospho-JNK in bovine blastocysts produced in vitro (Experiment 12). Shown in panel A are representative images of embryos labeled with phospho-JNK (red) and Hoechst (blue) that were treated at the blastocyst stage with $0,0.5,1 \mathrm{or} 2.5 \mu \mathrm{g} / \mathrm{mL}$ of recombinant WNT11 and harvested $6 \mathrm{~h}$ later. Shown in panel B are average values of intensity of fluorescence of phospho-JNK in the whole area of the embryo ( $n=49$ embryos). ${ }^{* * *} P<0.0001$ from $0 \mathrm{ng} / \mathrm{mL}$. 
signaling is partially silenced at the morula and blastocyst stages. To further explore this idea, two experiments were conducted to evaluate whether a key feature of canonical WNT signaling, nuclear localization of CTNNB1, occurs during preimplantation embryonic development.

For Experiment 3, an antibody recognizing both active (non-phosphorylated) and inactive (phosphorylated) CTNNB1 was used to determine the localization of total CTNNB1. Representative images are shown in Fig. 2. Regardless of stage of development, most immunoreactive CTNNB1 was localized to cell membranes; immunoreactive protein in the nucleus was absent in all but the occasional cell.

As nuclear CTNNB1 was not observed at any developmental stage, Experiment 4 was performed using an antibody specific for active CTNNB1 (i.e., non-phosphorylated CTNNB1) (Fig. 3). As for total CTNNB1, most active CTNNB1 was localized to plasma membranes and, except for the scattered nucleus, nuclear localization was absent at all developmental stages.

\section{Failure of canonical WNT activators to induce localization of nuclear active CTNNB1 (Experiments 5-8)}

One possible reason for the lack of nuclear CTNNB1 in embryos is the absence of stimulation by canonical WNTs. To test this hypothesis, three experiments were conducted to evaluate the localization of active CTNNB1 after stimulation of WNT signaling. In Experiment 5, embryos were treated with a GSK3 inhibitor at the 3-4-cell, 5-8-cell, 9-16-cell and morula stages of development. Inhibition of GSK3 leads to the accumulation of CTNNB1 and import into the nucleus (Yuan et al. 2005). Some control and GSK3 inhibitor-treated embryos were also treated with leptomycin to block nuclear exportins. This treatment was added to enhance nuclear localization of CTNNB1 in case nuclear CTNNB1 induced by GSK3 inhibition is rapidly exported from the nucleus. Representative images are shown in Fig. 4. Active CTNNB1 remained localized to non-nuclear regions

Table 2 Effect of $2.5 \mu \mathrm{g} / \mathrm{mL}$ WNT11 from Day 5 to Day 7 after insemination on the development of bovine embryos to the blastocyst stage at Day 7 after insemination. ${ }^{\text {a }}$

\begin{tabular}{lcccc}
\hline & & \multicolumn{3}{c}{ Blastocyst cell number } \\
\cline { 3 - 5 } Treatment & Percent blastocyst & Total & TE & ICM \\
\hline Vehicle & $17.8 \pm 2.5$ & $127 \pm 6$ & $89 \pm 5$ & $38 \pm 3$ \\
WNT11 & $25.5 \pm 2.7$ & $138 \pm 6$ & $93 \pm 4$ & $45 \pm 3$ \\
$P$ value & 0.042 & 0.210 & 0.529 & 0.137 \\
\hline
\end{tabular}

${ }^{a}$ Data are the least-squares means \pm S.E.M. of results. Data on percent blastocyst represent the percent of inseminated oocytes that developed to the blastocyst stage. The total number of oocytes was 484. Blastocyst cell number was evaluated for 74 embryos. of the cells and to the plasma membrane in particular. With the exception of the occasional cell, there was no accumulation of CTNNB1 in the nucleus at any stage of development.

For Experiment 6, embryos at the 5-8-cell or morulae stages of development were treated with either the WNT agonist AMBMP or human WNT1 and localization of active CTNNB1 was determined after 1 , 6,24 and $48 \mathrm{~h}$ of incubation. Although both treatments increased the intensity of labeling for active CTNNB1 in the plasma membrane, there was no accumulation of detectable CTNNB1 in the nucleus (Fig. 5A). For Experiments 7 (results not shown) and 8 (Fig. 5B), treatment of morulae with AMBMP at Day 5 or GSK3 inhibitor on Day 6 after insemination also failed to increase nuclear labeling with CTNNB1 in resultant blastocysts at Day 7. Both treatments did increase the immunoreactive active CTNNB1 localized in the plasma membrane (Fig. 5B).

\section{Localization of active CTNNB1 in mouse and bovine embryos evaluated by confocal microscopy (Experiments 9 and 10)}

As found for bovine embryos using epifluorescence microscopy, there was no observable active CTNNB1 in the nucleus of mouse 5-8-cell embryos (Fig. 6A). Similarly, no active CTNNB1 was observed in the nuclei of bovine embryos when embryos were examined by confocal microscopy (Fig. 6B).

\section{Nuclear localization of CTNNB1 in bovine embryonic fibroblast cells after activation of canonical WNT signaling (Experiment 11)}

To test whether the absence of nuclear localization of active CTNNB1 was a unique feature of preimplantation embryos, localization of the protein was also examined in BEF cells derived from bovine embryonic fibroblasts. In these cells, punctuate labeling of active CTNNB1 was observed in the nucleus of a fraction of cells (Supplementary Fig. 1). The proportion of cells depicting nuclear localization of active CTNNB1 was 310/763 (40.6\%) for control cells vs $67 / 148(45.3 \%)$ for cells treated with AMBMP $(P=0.29$ for difference from control) and $750 / 839(89.4 \%)$ for cells treated with GSK3 inhibitor $(P<0.0001$ for difference from control).

\section{Actions of WNT11 on phosphorylation of the non- canonical signaling protein JNK and development to the blastocyst stage (Experiments 12 and 13)}

Immunoreactive phospho-JNK was localized in nuclei (Fig. 7A). Moreover, the pattern of nuclear labeling of phospho-JNK was punctuate. The degree of labeling varied between cells although labeling was not consistently elevated in TE or ICM. Treatment of 
blastocysts with human recombinant WNT11 caused a significant increase in intensity of labeling of phosphoJNK at $2.5 \mu \mathrm{g} / \mathrm{mL}(P<0.0001)$ but not at 0.5 or $1 \mu \mathrm{g} / \mathrm{mL}$ (Fig. 7B).

In Experiment 13, effect of WNT11 on development and blastocyst cell number was determined (Table 2). Treatment with WNT11 increased the proportion of oocytes that developed to the blastocyst stage $(P=0.042)$ but had no effect on number of ICM, TE or total cells in the resulting blastocysts.

\section{Discussion}

The mouse embryo does not require canonical WNT signaling for either development to the blastocyst stage or ESC identity, expansion or self-renewal (Huelsken et al. 2000, Kemler et al. 2004, Xie et al. 2008, Lyashenko et al. 2011). The situation for other species is less clear. Here, we show that one of the characteristics of preimplantation development in the cow is a temporal decrease in the expression of key genes involved in WNT signaling along with a paucity of nuclear CTNNB1, even after stimulation of the embryo with molecules that activate canonical WNT signaling. These observations are consistent with the idea that, like the mouse, canonical WNT signaling is dispensable for blastocyst development in the cow. In contrast, non-canonical WNT signaling improved embryonic development because WNT11 increased the proportion of embryos becoming blastocysts while also increasing the phosphorylation of JNK, a central player in WNT/ planar cell polarity (PCP) pathway (Zeke et al. 2016). Observed changes in gene expression also mean that, like for the human (Krivega et al. 2015), characteristics of WNT signaling are likely to change during development. By the blastocyst stage, WNT signaling may play different roles in the ICM and TE because of the differences in expression of several important genes in the WNT signaling system.

A key observation of the current series of experiments was, with rare exceptions, the absence of observable immunoreactive CTNNB1 in the nucleus of embryos at every stage examined. Failure to observe nuclear CTNNB1 was not because of failure of the antibodies used to recognize the molecule because immunoreactive total and active CTNNB1 could be localized to the plasma membrane. Lack of nuclear CTNNB1 was observed even after embryos were treated with molecules expected to activate canonical WNT signaling including a GSK3 inhibitor, the WNT agonist AMBMP (Liu et al. 2005) or the canonical WNT1 (Shimizu et al. 1997, Yuan et al. 2005). The lack of nuclear CTNNB1 was not due to rapid export from the nucleus because inhibition of nuclear exportins with leptomycin did not lead to the accumulation of CTNNB1 in the nucleus. Failure of the molecules to induce nuclear localization was not because the molecules were inactive because all three WNT activators increased active CTNNB1 associated with the plasma membrane and because GSK3 inhibition increased the percent of cells with nuclear CTNNB1 in cells of the BEF cell line. Immunolabeling of nuclear active CTNNB1 in BEF cells was characterized by a punctuate pattern resembling that previously described in newly differentiated chondrocytes (Guo et al. 2004) and intrahepatic cholangiocarcinoma cells (Wang et al. 2015).

An absence of CTNNB1 in the nucleus of the preimplantation embryo may be a widespread phenomenon in the mammal, at least for certain stages of development. In the human embryo, GSK3Binduced accumulation of CTNNB1 in the nucleus depends upon stage of development, with accumulation being attenuated after Day 3 of development and absent in blastocysts (Krivega et al. 2015). In the pig, immunoreactive nuclear CTNNB1 was faint in expanded blastocysts and absent in hatching blastocysts (Lim et al. 2013). Moreover, accumulation in the nucleus was not induced by LiCl inhibition of GSK3 (Lim et al. 2013).

Results with respect to the mouse are contradictory. No nuclear CTNNB1 was detected in mouse blastocysts in one study (Kemler et al. 2004), whereas active CTNNB1 was observed in the nucleus of embryos at the 1-cell, 2-cell, 4-cell, 8-cell, morula and blastocyst stages of development in another (Xie et al. 2008). Present results fail to replicate findings of nuclear CTNNB1 in mouse 5-8-cell embryos even though the antibody used in the present experiment was the same as used earlier (Xie et al. 2008).

The findings that CTNNB1 does not translocate to the nucleus in the bovine embryo after treatment with canonical WNT activators does not mean that WNTs are not involved in the regulation of embryonic development. In addition to canonical signaling, there are a variety of other signaling cascades activated by WNTs termed non-canonical pathways (Filmus et al. 2008, Chien et al. 2009, van Amerongen \& Nusse 2009, Gao 2012). Some of these pathways use FZD as a receptor (PCP- and $\mathrm{Ca}^{++}$ mediated signaling), whereas others use other receptor molecules such as ROR and RYK. Individual WNTs preferentially stimulate canonical or non-canonical signaling depending upon the ability to bind FZD and recruit LRP5/6 and other co-receptor molecules. Thus, some documented actions of WNTs on the preimplantation embryo, for example, promotion of TE development in human embryos by WNT3 (Krivega et al. 2015), could involve signaling through one or more pathways independent of accumulation of CTNNB1 in the nucleus. Here, we show that WNT11, which is considered to preferentially activate non-canonical pathways (Flaherty \& Dawn 2008, Uysal-Onganer \& Kypta 2012), can activate a key component of the PCP pathway in bovine blastocysts by phosphorylating the signaling kinase JNK in the nucleus. Activation of JNK 
has been implicated in actions of WNT11 in other cells (Pandur et al. 2002, Cha et al. 2008, Chen et al. 2014, Geetha-Loganathan et al. 2014) although, under certain circumstances, WNT11 can inhibit JNK signaling (Railo et al. 2008). The observation that activated JNK was localized to the nucleus suggests that the protein translocates to the nucleus after activation, as has been described for other cells (Schreck et al. 2011, Coffey 2014). Furthermore, WNT11 participates in the regulation of preimplantation developmental processes because addition of exogenous WNT11 to the culture medium resulted in higher proportion of inseminated oocytes that developed to the blastocyst stage. Further investigations are needed to unravel the downstream effect of this WNT in the preimplantation bovine embryo, but the nuclear localization of phosphoJNK in response to WNT11 suggests an effect on gene expression (reviewed in Zeke et al. 2016).

In addition, although WNT activation did not cause accumulation of CTNNB1 in the nucleus in bovine embryos, it did increase CTNNB1 in the embryo, with the protein being localized primarily to the plasma membrane. Similar effects have been observed in human embryos (Krivega et al. 2015). Thus, certain actions of WNT on the embryo could involve signal transduction pathways using membrane-bound CTNNB1. In mouse embryonic stem cells, CTNNB1 bound to E-cadherin is required for the expression of Klf4 and Nanog via STAT3 phosphorylation (Hawkins et al. 2012). It may also be possible that activation of WNT signaling does lead to some accumulation of CTNNB1 in the nucleus but at amounts too low to be detected by immunofluorescence. Further investigation is needed to understand the alternative WNT signaling pathways regulating developmental processes, as well as the role of each of these pathways in preimplantation embryo development.

Analysis of gene expression during development is consistent with a reduction in WNT signaling as the embryo develops. In Experiment 1, transcript abundance for all genes examined declined to a nadir at the morula or blastocyst stage of development. This was true for the WNT co-receptors, $L R P 5$ and $L R P 6$, the canonical WNT antagonist $D K K 1$, two WNT-dependent transcription factors, LEF1 and TCF7, as well as two repressors of WNTdependent transcription factors, LOC505120 (encodes for GROUCHO-like protein) and AES. The decline in gene expression is not an artifact of in vitro fertilization or culture because similar developmental patterns of gene expression were seen for 6 of the 7 genes for embryos that developed in vivo (Supplementary Table 3 in Jiang et al. 2014). The only exception was for $A E S$, which rose in transcript abundance at the blastocyst stage for in vivo embryos (Jiang et al. 2014) but remained low for in vitroproduced embryos. It is possible that the developmental decline in abundance of most transcripts examined is part of the large-scale destruction of maternally derived
mRNA in the oocyte after fertilization (Tadros \& Lipshitz 2009, Graf et al. 2014).

More research is required, but analysis of differences in gene expression between the ICM and TE of the blastocyst are consistent with the idea that WNT signaling functions differently in the two cell types. Genes upregulated in the TE included three receptors or co-receptors (FZD1, FZD7 and LRP6) and two genes involved in the inhibition of canonical WNT signaling (APC and SFRP1). Expression of WNT6 was also upregulated in the TE. This WNT, which can promote the differentiation of primitive endoderm (Krawetz \& Kelly 2008), functions as a canonical WNT when binding FZD $1 / 2 / 7$ and as a non-canonical WNT when binding FZD 5/8 (Schmidt et al. 2007, Lhomond et al. 2012, Li et al. 2014). Perhaps WNT6 is secreted by TE cells to participate in the differentiation of cells of the ICM to primitive endoderm.

In conclusion, the accumulation of CTNNB1 in the nucleus in response to canonical WNT activators is blocked in the preimplantation bovine embryo. Moreover, there is a decline in expression of several genes important for canonical WNT signaling as the embryo advances in development. In contrast, at least one non-canonical signaling pathway involving JNK and the PCP pathway, can be activated in the bovine preimplantation embryo. Moreover, WNT11, which causes JNK activation, improves the competence of the embryo to develop to the blastocyst stage. Thus, some actions of WNTs on the preimplantation embryo are likely to involve signaling through mechanisms independent of nuclear CTNNB1. Differences in gene expression between the TE and ICM mean that, by the blastocyst stage, WNT signaling may play different roles in the ICM and TE.

\section{Supplementary data}

This is linked to the online version of the paper at http://dx.doi. org/10.1530/REP-16-0610.

\section{Declaration of interest}

The authors declare that there is no conflict of interest that could be perceived as prejudicing the impartiality of the research reported.

\section{Funding}

This work was supported by Agriculture and Food Research Initiative Competitive Grant no. 2011-67015-30688 from the USDA National Institute of Food and Agriculture. Data were presented in part at 41st Annual Conference of the IETS, January 10-13, 2015, Versailles, France.

\section{Acknowledgements}

The authors thank William Rembert and Eddie Cummings, for ovary collection; owners and employees of Central 
Beef Packing Co. (Center Hill, FL), for providing ovaries; Southeastern Semen Services (Wellborn, FL), for donation of semen; and Douglas Smith and the Cell and Tissue Analysis Core of the McKnight Brain Institute of the University of Florida for capturing confocal images. Authors also thank Amy Ralston, Michigan State University, for the advice on use of leptomycin and the anonymous reviewers, for careful scrutiny of the data.

\section{References}

Amerongen RV, Mikels A \& Nusse R 2008 Alternative Wnt signaling is initiated by distinct receptors. Cell Biology 1 1-6. (doi:10.1126/ scisignal.135re9)

van Amerongen R \& Nusse R 2009 Towards an integrated view of Wnt signaling in development. Development 136 3205-3214. (doi:10.1242/ dev.033910)

Aparicio IM, Fair T \& Lonergan P 2000 Identification and regulation of glycogen synthase kinase-3 during bovine embryo development. Reproduction 140 83-92. (doi:10.1530/REP-10-0040)

Berg DK, Smith CS, Pearton DJ, Wells DN, Broadhurst R, Donnison M \& Pfeffer PL 2011 Trophectoderm lineage determination in cattle. Developmental Cell 20 244-255.

Cadigan KM \& Nusse R 1997 Wnt signalling: a common theme in animal development. Genes and Development 11 3286-3305. (doi:10.1101/ gad.11.24.3286)

Caneparo L, Huang Y, Staudt N, Tada M, Ahrendt R, Kazanskaya O, Niehrs C \& Houart C 2007 Dickkopf-1 regulates gastrulation movements by coordinated modulation of $\mathrm{Wnt} / \mathrm{\beta}$-catenin and $\mathrm{Wnt} /$ PCP activities, through interaction with the Dally-like homolog Knypek. Genes and Development 21 465-480. (doi:10.1101/ gad.406007)

Cha S-W, Tadjuidje E, Tao Q, Wylie C \& Heasman J 2008 Wnt5a and Wnt11 interact in a maternal Dkk1-regulated fashion to activate both canonical and non-canonical signaling in Xenopus axis formation. Development 135 3719-3729. (doi:10.1242/dev.029025)

Chen M, Qian C, Bi LL, Zhao F, Zhang GY, Wang ZQ, Gan XD \& Wang YG 2014 Enrichment of cardiac differentiation by a large starting number of embryonic stem cells in embryoid bodies is mediated by the Wnt11-JNK pathway. Biotechnology Letters 37 475-481. (doi:10.1007/s10529-0141700-5)

Chien AJ, Conrad WH \& Moon RT 2009 A Wnt survival guide: from flies to human disease. Journal of Investigative Dermatology 129 1614-1627. (doi:10.1038/jid.2008.445)

Coffey ET 2014 Nuclear and cytosolic JNK signalling in neurons. Nature Reviews Neuroscience 15 285-299. (doi:10.1038/nrn3729)

Denicol AC, Dobbs KB, McLean KM, Carambula SF, Loureiro B \& Hansen PJ 2013 Canonical WNT signaling regulates development of bovine embryos to the blastocyst stage. Scientific Reports 31266. (doi:10.1038/srep01266)

Denicol AC, Block J, Kelley DE, Pohler KG, Dobbs KB, Mortensen CJ, Ortega MS \& Hansen PJ 2014 The WNT signaling antagonist Dickkopf-1 directs lineage commitment and promotes survival of the preimplantation embryo. FASEB Journal 28 3975-3986. (doi:10.1096/ fj.14-253112)

Dobbs K, Khan F, Sakatani M, Moss J, Ozawa M, Ealy A \& Hansen PJ 2013 Regulation of pluripotency of inner cell mass and growth and differentiation of trophectoderm of the bovine embryo by colony stimulating factor 2. Biology of Reproduction 89 141. (doi:10.1095/ biolreprod.113.113183)

Filmus J, Capurro M \& Rast J 2008 Glypicans. Genome Biology 9224. (doi:10.1186/gb-2008-9-5-224)

Flaherty MP \& Dawn B 2008 Noncanonical Wnt11 signaling and cardiomyogenic differentiation. Trends in Cardiovascular Medicine $\mathbf{1 8}$ 260-268. (doi:10.1016/j.tcm.2008.12.001)

Fleming TP, Sheth B \& Fesenko I 2001 Cell adhesion in the preimplantation mammalian embryo and its role in trophectoderm differentiation and blastocyst morphogenesis. Frontiers in Bioscience 6 1000-1007. (doi:10.2741/A662)
Gao B 2012 Wnt regulation of planar cell polarity (PCP). Current Topics in Developmental Biology 101 263-295. (doi:10.1016/b978-0-12394592-1.00008-9)

Geetha-Loganathan P, Nimmagadda S, Fu K \& Richman JM 2014 Avian facial morphogenesis is regulated by JNK/PCP wingless-related (WNT) signaling. Journal of Biological Chemistry 289 24153-24167. (doi:10.1074/jbc.M113.522003)

Goossens K, Van Poucke M, Van Soom A, Vandesompele J, Van Zeveren A \& Peelman LJ 2005 Selection of reference genes for quantitative real-time PCR in bovine preimplantation embryos. $B M C$ Developmental Biology 5 27. (doi:10.1186/1471-213X-5-27)

Graf A, Krebs S, Heininen-brown M, Zakhartchenko V, Blum H \& Wolf E 2014 Genome activation in bovine embryos: review of the literature and new insights from RNA sequencing experiments. Animal Reproduction Science 149 46-58. (doi:10.1016/j.anireprosci.2014.05.016)

Guo X, Day TF, Jiang X, Garrett-Beal L, Topol L \& Yang Y 2004 $\mathrm{Wnt} / \beta$-catenin signaling is sufficient and necessary for synovial joint formation. Genes and Development 18 2404-2417. (doi:10.1101/ gad.1230704)

Hawkins K, Mohamet L, Ritson S, Merry CLR \& Ward CM 2012 E-cadherin and, in its absence, $\mathrm{N}$-cadherin promotes Nanog expression in mouse embryonic stem cells via STAT3 phosphorylation. Stem Cells 30 1842-1851. (doi:10.1002/stem.1148)

He T, Sparks AB, Rago C, Hermeking H, Zawel L, Costa LT, Morin PJ, Vogelstein B \& Kinzler KW 1998 Identification of C-MYC as a target of the APC pathway. Science 281 1509-1512. (doi:10.1126/ science.281.5382.1509)

Huelsken J, Vogel R, Brinkmann V, Erdmann B, Birchmeier C \& Birchmeier W 2000 Requirement for $\beta$-catenin in anterior-posterior axis formation in mice. Cell Biology 148 567-578. (doi:10.1083/ jcb.148.3.567)

Jiang Z, Sun J, Dong H, Luo O, Zheng X, Obergfell C, Tang Y, Bi J, $\mathbf{O}^{\prime}$ Neill R, Ruan Y et al. 2014 Transcriptional profiles of bovine in vivo pre-implantation development. BMC Genomics 15756. (doi:10.1186/1471-2164-15-756)

Kannampuzha-Francis J, Tribulo P \& Hansen PJ 2017 Actions of activin A, connective tissue growth factor, hepatocyte growth factor and teratocarcinoma-derived growth factor 1 on the development of the bovine preimplantation embryo. Reproduction, Fertility and Development [in press]. (doi:10.1071/rd16033)

Kemler R, Hierholzer A, Kanzler B, Kuppig S, Hansen K, Taketo MM, de Vries WN, Knowles BB \& Solter D 2004 Stabilization of $\beta$-catenin in the mouse zygote leads to premature epithelial-mesenchymal transition in the epiblast. Development 131 5817-5824. (doi:10.1242/ dev.01458)

Kim H, Wu J, Ye S, Tai C-I, Zhou X, Yan H, Li P, Pera M \& Ying Q-L 2013 Modulation of $\beta$-catenin function maintains mouse epiblast stem cell and human embryonic stem cell self-renewal. Nature Communications 4 2403. (doi:10.1038/ncomms2329)

Kohn AD \& Moon RT 2005 Wnt and calcium signaling: $\beta$-cateninindependent pathways. Cell Calcium 38 439-446. (doi:10.1016/j. ceca.2005.06.022)

Krawetz R \& Kelly GM 2008 Wnt6 induces the specification and epithelialization of F9 embryonal carcinoma cells to primitive endoderm. Cellular Signalling 20 506-517. (doi:10.1016/j. cellsig.2007.11.001)

Krivega M, Essahib W \& Van de Velde H 2015 WNT3 and membraneassociated $\beta$-catenin regulate trophectoderm lineage differentiation in human blastocysts. Molecular Human Reproduction 21 711-722. (doi:10.1093/molehr/gav036)

Kühl M, Sheldahl LC, Park M, Miller JR \& Moon RT 2000 The Wnt/Ca ${ }^{2+}$ pathway: a new vertebrate Wnt signaling pathway takes shape. Trends in Genetics 16 279-283. (doi:10.1016/S0168-9525(00)02028-X)

Lappas M 2014 GSK3 $\beta$ is increased in adipose tissue and skeletal muscle from women with gestational diabetes where it regulates the inflammatory response. PLOS ONE 9 1-23. (doi:10.1371/journal.pone.0115854)

Lhomond G, McClay DR, Gache C \& Croce JC 2012 Frizzled 1/2/7 signaling directs $\beta$-catenin nuclearisation and initiates endoderm specification in macromeres during sea urchin embryogenesis. Development 139 816-825. (doi:10.1242/dev.072215)

Li R, Wang C, Tong J, Su Y, Lin Y, Zhou X \& Ye L 2014 WNT6 promotes the migration and differentiation of human dental pulp cells partly through 
c-Jun N-terminal kinase signaling pathway. Journal of Endodontics 40 943-948. (doi:10.1016/j.joen.2013.12.023)

Lim KT, Gupta MK, Lee SH, Jung YH, Han DW \& Lee HT 2013 Possible involvement of $\mathrm{Wnt} / \beta$-catenin signaling pathway in hatching and trophectoderm differentiation of pig blastocysts. Theriogenology $\mathbf{7 9}$ 284-290. (doi:10.1016/j.theriogenology.2012.08.018)

Liu J, Wu X, Mitchell B, Kintner C, Ding S \& Schultz PG 2005 A smallmolecule agonist of the Wnt signaling pathway. Angewandte Chemie 44 1987-1990. (doi:10.1002/anie.200462552)

Liu S, Zhang E, Yang M \& Lu L 2014 Overexpression of Wnt11 promotes chondrogenic differentiation of bone marrow-derived mesenchymal stem cells in synergism with TGF- $\beta$. Molecular and Cellular Biochemistry 390 123-131. (doi:10.1007/s11010-014-1963-0)

Logan CY \& Nusse R 2004 The Wnt signaling pathway in development and disease. Annual Review of Cell and Developmental Biology 20 781-810. (doi:10.1146/annurev.cellbio.20.010403.113126)

Lyashenko N, Winter M, Migliorini D, Biechele T, Moon RT \& Hartmann C 2011 Differential requirement for the dual functions of $\beta$-catenin in embryonic stem cell self-renewal and germ layer formation. Nature Cell Biology 13 753-761. (doi:10.1038/ncb2260)

MacDonald BT, Tamai K \& He X 2009 Wnt/ $\beta$-Catenin signaling: components, mechanisms, and diseases. Developmental Cell 17 9-26. (doi:10.1016/j.devcel.2009.06.016)

Morosan-Puopolo G, Balakrishnan-Renuka A, Yusuf F, Chen J, Dai F, Zoidl G, Lüdtke TH-W, Kispert A, Theiss C, Abdelsabour-Khalaf M et al. 2014 Wnt1 1 is required for oriented migration of dermogenic progenitor cells from the dorsomedial lip of the avian dermomyotome. PLOS ONE 9 e92679. (doi:10.1371/journal.pone.0092679)

Ortega MS, Rocha-Frigoni NAS, Mingoti GZ, Roth Z \& Hansen PJ 2016 Modification of embryonic resistance to heat shock in cattle by melatonin and genetic variation in HSPA1L. Journal of Dairy Science 99 9152-9164. (doi:10.3168/jds.2016-11501)

Ozawa M \& Hansen PJ 2011 A novel method for purification of inner cell mass and trophectoderm cells from blastocysts using magnetic activated cell sorting. Fertility and Sterility 95 799-802. (doi:10.1016/j. fertnstert.2010.10.006)

Ozawa M, Sakatani M, Yao J, Shanker S, Yu F, Yamashita R, Wakabayashi S, Nakai K, Dobbs KB, Sudano MJ et al. 2012 Global gene expression of the inner cell mass and trophectoderm of the bovine blastocyst. BMC Developmental Biology 12 33. (doi:10.1186/1471213X-12-33)

Pandur P, Lasche M, Leonard ME \& Kuhl M 2002 Wnt-11 activation of a non-canonical Wnt signalling pathway is required for cardiogenesis. Nature 418 636-641. (doi:10.1038/nature00921)

Parrish J, Susko-Parrish JL, Leibfried-Rutledge ML, Critser ES, Eyestone WH \& First NL 1986 Bovine in vitro fertilization with frozenthawed semen. Theriogenology 25 591-600. (doi:10.1016/0093691X(86)90143-3)

Railo A, Nagy II, Kilpeläinen P \& Vainio S 2008 Wnt-11 signaling leads to down-regulation of the $\mathrm{Wnt} / \beta$-catenin, JNK/AP-1 and NF-кB pathways and promotes viability in the $\mathrm{CHO}-\mathrm{K} 1$ cells. Experimental Cell Research 314 2389-2399. (doi:10.1016/j.yexcr.2008.04.010)

Sato N, Meijer L, Skaltsounis L, Greengard P \& Brivanlou AH 2004 Maintenance of pluripotency in human and mouse embryonic stem cells through activation of Wnt signaling by a pharmacological GSK-3specific inhibitor. Nature Medicine 10 55-63. (doi:10.1038/nm979)

Schmidt C, McGonnell IM, Allen S, Otto A \& Patel K 2007 Wnt6 controls amniote neural crest induction through the non-canonical signaling pathway. Developmental Dynamics 236 2502-2511. (doi:10.1002/ dvdy.21260)

Schreck I, Al-Rawi M, Mingot JM, Scholl C, Diefenbacher ME, O' Donnell P, Bohmann D \& Weiss C 2011 C-Jun localizes to the nucleus independent of its phosphorylation by and interaction with JNK and vice versa promotes nuclear accumulation of JNK. Biochemical and Biophysical Research Communications 407 735-740. (doi:10.1016/j. bbrc.2011.03.092)

Seifert JRK \& Mlodzik M 2007 Frizzled/PCP signalling: a conserved mechanism regulating cell polarity and directed motility. Nature Reviews Genetics 8 126-138. (doi:10.1038/nrg2042)

Shimizu H, Julius MA, Giarré M, Zheng Z, Brown AM \& Kitajewski J 1997 Transformation by Wnt family proteins correlates with regulation of $\beta$-catenin. Cell Growth and Differentiation 8 1349-1358.

Sokol SY 2011 Maintaining embryonic stem cell pluripotency with Wnt signaling. Development 138 4341-4350. (doi:10.1242/dev.066209)

Tadros W \& Lipshitz HD 2009 The maternal-to-zygotic transition: a play in two acts. Development 136 3033-3042. (doi:10.1242/dev.033183)

Tahinci E, Thorne CA, Franklin JL, Salic A, Christian KM, Lee LA, Coffey RJ \& Lee E 2007 Lrp6 is required for convergent extension during Xenopus gastrulation. Development 134 4095-4106. (doi:10.1242/ dev.010272)

Tetsu O \& McCormick F $1999 \beta$-Catenin regulates expression of cyclin D1 in colon carcinoma cells. Nature 398 422-426. (doi:10.1038/18884)

Uysal-Onganer P \& Kypta RM 2012 Wnt11 in 2011 - the regulation and function of a non-canonical Wnt. Acta Physiologica 204 52-64. (doi:10.1111/j.1748-1716.2011.02297.x)

Veeman MT, Axelrod JD \& Moon RT 2003 A second canon: functions and mechanisms of $\beta$-catenin-independent Wnt signaling. Developmental Cell 5 367-377. (doi:10.1016/S1534-5807(03)00266-1)

Wang J, Zhang K, Wang J, Wu X, Liu X, Li B, Zhu Y, Yu Y, Cheng Q, Hu Z et al. 2015 Underexpression of LKB1 tumor suppressor is associated with enhanced Wnt signaling and malignant characteristics of human intrahepatic cholangiocarcinoma. Oncotarget 6 18905. (doi:10.18632/ oncotarget.4305)

Wolff B, Sanglier JJ \& Wang Y 1997 Leptomycin B is an inhibitor of nuclear export: inhibition of nucleo-cytoplasmic translocation of the human immunodeficiency virus type 1 (HIV-1) Rev protein and Rev-dependent mRNA. Chemistry and Biology 4 139-147. (doi:10.1016/S10745521(97)90257-X)

Wray J, Kalkan T, Gomez-Lopez S, Eckardt D, Cook A, Kemler R \& Smith A 2011 Inhibition of glycogen synthase kinase-3 alleviates Tcf3 repression of the pluripotency network and increases embryonic stem cell resistance to differentiation. Nature Cell Biology 13 838-845. (doi:10.1038/ncb2267)

Xie H, Tranguch S, Jia X, Zhang H, Das SK, Dey SK, Kuo CJ \& Wang H 2008 Inactivation of nuclear Wnt- $\beta$-catenin signaling limits blastocyst competency for implantation. Development 135 717-727. (doi:10.1242/ dev.015339)

Yuan J, Zhang J, Wong BW, Si X, Wong J, Yang D \& Luo H 2005 Inhibition of glycogen synthase kinase $3 \beta$ suppresses coxsackievirus-induced cytopathic effect and apoptosis via stabilization of $\beta$-catenin. Cell Death and Differentiation 12 1097-1106. (doi:10.1038/sj.cdd.4401652)

Zeke A, Misheva M, Remenyi A \& Bogoyevitch MA 2016 JNK signaling: regulation and functions based on complex protein-protein partnerships. Microbiology and Molecular Biology Reviews 80 793-835. (doi:10.1128/ MMBR.00043-14)

Received 4 October 2016

First decision 31 October 2016

Revised manuscript received 7 December 2016

Accepted 9 January 2017 